\title{
The choice of mining development strategy based on the improved Bayes criterion
}

\author{
Yevhen Lapshin ${ }^{1}$, Borys Blyuss ${ }^{1}$, Serhii Dziuba ${ }^{1, *}$, and Larysa Tatarko ${ }^{2}$ \\ ${ }^{1}$ Institute of Geotechnical Mechanics named by N. Poljakov of National Academy of Sciences of \\ Ukraine, 49005, Dnipro, Simferopolska Str., 2a, Ukraine \\ ${ }^{2}$ Ukrainian State University of Chemical Technology, 49600, Dnipro, Haharina Ave., 8, Ukraine
}

\begin{abstract}
The choice of mining development strategies is based on the main indicators of mining and geological conditions that characterize mineral deposits. The purpose of the research is to argue the application of the improved Bayes criterion when choosing rational mining development strategies by taking into account the complex mining and geological conditions. The methodology of decision-making in terms of managing geotechnical systems depends on whether or not the probabilities of the conditions and dynamics of the parameters of rocks and soils are known during the development of mineral deposits, as well as the construction of infrastructure facilities. If the probabilities are unknown, then there is the problem of making decisions in the conditions of uncertainty of the initial data to assess the efficiency of the mining enterprises. And if the probabilities are known, then we are dealing with the task of making decisions in conditions of risk and assess the safety of mining operations. The improvement of the Bayes criterion enables us to determine, with an acceptable range of changes in efficiency, a strategy which provides more likely an increase in economic efficiency compared to a strategy selected using the traditional Bayes criterion.
\end{abstract}

\section{Introduction}

Various types of mining engineering works, the development of industrial regions and underground infrastructure projects, an increase in traffic flows, etc. lead to constant increase in the dynamic loads intensity on the geological environment. The complexity of modeling geological conditions is associated mainly with the insufficient correspondence of real dynamic loads to experimental and well-known patterns of changes in rock properties to experimental conditions. Currently research development in the field of dynamic soil instability is characterized by the fact that the approaches to modeling and assessing different nature dynamic loads are completely different. When choosing a development strategy in the framework of infrastructure projects, the informed decisions adoption based on game theory becomes increasingly important [1-3].

Analysis of cyclic alternating movements in rock formations shows that the main

\footnotetext{
${ }^{*}$ Corresponding author: sergejdzuba@gmail.com
} 
geological environment property is the continuity of its movement. The engineering structures, infrastructure facilities located on disturbed fractures and waterlogged soils, especially in zones of tectonic faults, are more likely exposed to emergencies.

So far the general patterns of manifestation of various forms of dynamic soil instability have been studied insufficiently and unevenly. Neither the effect of the parameters of the natural stress state of soils nor the degree of their overconsolidation on the behavior under dynamic loads and water cut has been investigated; there is also no information on the role of the degree of asymmetry of the existing loads on the soils dynamic stability. Technical difficulties reflection of complex dynamic loads correct experimental modeling is the development of increasingly complex, cumbersome and expensive equipment. The consequence of technical difficulties of correct experimental modeling of complex dynamic loads is the development of increasingly complex, bulky and expensive equipment. All these factors determine the relevance of the applying the game theory when planning mining operations in complex geological conditions.

The necessity of decision-making is essential in all areas of human activity (sociology, medicine, economics, military affairs, etc.). The game theory is widely used to support decision making [4-7].

Shubik's words "the review of numerous particular directions could contain not less than 70-80 pages" indicate a large number of published works on game theory and its practical application [8].

The importance of the game theory development and application in economics is illustrated by the fact that 15 scientists were awarded with 6 Nobel Prizes in economics from 1994 to 2012 [9].

The game theory is an effective decision-making tool in planning of mining operations and managing the development of mining enterprises [10, 11].

The decision-making methodology in a game with geotechnical systems depends on whether or not the probabilities of the rocks and soils dynamics states and conditions are known during the development of mineral deposits, as well as the construction of infrastructure facilities. If the probabilities are unknown, then there is the problem of making decisions in the conditions of uncertainty of the initial data to assess the efficiency of the mining enterprises. And if the probabilities are known, then we are dealing with the task of making decisions in conditions of risk and assess the safety of mining operations.

The research aim is to justify the improved Bayes criterion application when choosing rational mining development strategies taking into account complex mining and geological conditions.

The specificities of the application of criteria in conditions of uncertainty are studied and analyzed in course of the research [1].

\section{Methodology}

Let us consider the problem of making decisions in a risky environment and assessing the safety of mining engineering works [7, 9, 12, 13]. In this case, a mathematical model of game theory is used to describe and evaluate the characteristics of geotechnical systems. In this model, the management of the mining enterprise (managerial personnel) are the decision makers (DM), and the geotechnical system is rock formations, soils and the area adjacent to mineral deposits. So, the rock dynamics states and conditions probabilities are known, namely, hazard classes for rock emissions, soils filtration characteristics, porosity, hardness, temperature conditions, etc. This situation could be characterized by the words attributed to Einstein who once said that while nature may be subtle, it is not malicious [14]. The geotechnical system conditions probabilities can be obtained as a result of 
statistical studies (objective probabilities), or based on the opinions of experts (subjective probabilities).

The strategy sustainability is estimated by the average value of economic efficiency of safe excavation or rocks excavation risks in difficult mining and geological conditions, taking into account the probabilities of all geotechnical systems states. This approach is one of the most widely used [15]. When it is necessary to assess the economic efficiency of mining enterprises with justification of the maximum value of the result, a strategy with the maximum average should be used. If a minimum risk is needed, then we use the one with a minimum average. These extreme values of averages are called Bayes criterion.

Limitation of the Bayes criterion does not allow to choose the optimal strategy in situations when several strategies performance indicators differ by a small amount acceptable for the decision makers.

\section{Results and its discussion}

\subsection{Bayesian criterion regarding cost-effectiveness in safe mining}

We assume that the decision maker has $m$ strategies, and the geotechnical system could possibly have $n$ states. The values of the "economic efficiency of mining" $a_{i j}$ are known for the DM, taking into account the sustainable improvement of the mineral deposits development under the $i$ strategy $(i=\overline{1, m})$ and $j$ condition $(j=\overline{1, n})$ of the geotechnical system, the probability of which is $P_{j}$. The combination of elements $a_{i j}$ forms a matrix of the game $A$ with the size of $m \times n$.

The economic efficiency average values in the implementation of the ith strategy are calculated by the formula:

$$
\bar{a}_{i}=\sum_{j=1}^{n} P_{j} a_{i j}
$$

Thus, the Bayes criterion is

$$
B a=\max _{i} \bar{a}_{i}
$$

The strategy in which $\max _{i} \bar{a}_{i}$ is denoted as $S_{B a}$.

The formulas (1) and (2) are presented as follows

$$
\begin{gathered}
\bar{A}=A P^{T}, \\
B a=\max \bar{A}=\max \left(A P^{T}\right),
\end{gathered}
$$

where $\bar{A}$ is the mining economic efficiency average values matrix column; $A$ is matrix of values for evaluating the economic efficiency of mining operations; $P$ is probability row matrix and $T$ is the transpose symbol.

In addition to the traditional approach, we introduce a decrease $\Delta$ in the Bayes criterion acceptable for decision makers.

In case of strategies $S_{i}$ for which $\bar{A}_{i}$ is placed in interval $(B a-\Delta) \leq \bar{A}_{i} \leq B a$ there could be a better choice of strategy than $S_{B a}$. We will mark such a strategy with an asterisk, i.e. $S_{i}^{*}$. 
For $S_{i}^{*}$ in the matrix we select elements that are larger than $B a$ and and we determine the total probabilities of their implementation

$$
P_{i}^{*}(>B a)=\sum_{j}^{n} s_{j}
$$

where $s_{j}=\left\{\begin{array}{ll}P_{j}, & a_{i j} \leq B a \\ 0, & a_{i j}>B a\end{array}\right.$.

According to formula (5) we determine the total probabilities of $P_{B a}^{*}(>B a)$ and for strategy $A_{B a}$. If $P_{i}^{*}(>B a)>P_{B a}^{*}(>B a)$ then it is reasonable to choose the strategy $S_{i}^{*}$. If we have several strategies, preference should be given to one that could be implemented with higher probability.

With an allowable deviation $\Delta$ according to formula (5) we could define a strategy which is more probably to provide an increase in economic efficiency compared to a strategy selected using the traditional Bayes criterion. This strategy leads to the improvement of the Bayes criterion.

Let us consider the following example. There are four possible states of complex geological conditions that describe rock formations and soils $n=4$ with probabilities

$$
P=\left(\begin{array}{llll}
0.1 & 0.2 & 0.3 & 0.4
\end{array}\right) .
$$

The decision makers dispose of three strategies $(m=3)$ with a matrix of values for evaluating the economic efficiency of mining

$$
A=\left(\begin{array}{cccc}
1 & 4 & 4.7 & 1.8 \\
3 & 3.3 & 7 & 3 \\
4 & 6.8 & 5.5 & 2
\end{array}\right)
$$

The estimates of the economic efficiency of mining $a_{i j}$ are given in conditional units. $\Delta=0.5$ is allowed.

By plugging (6) and (7) in (3) we obtain

$$
\bar{A}=A P^{T}=\left(\begin{array}{cccc}
1 & 4 & 4.7 & 1.8 \\
3 & 3.3 & 7 & 3 \\
4 & 6.8 & 5.5 & 2
\end{array}\right)\left(\begin{array}{l}
0.1 \\
0.2 \\
0.3 \\
0.4
\end{array}\right)=\left(\begin{array}{l}
3.03 \\
4.26 \\
4.21
\end{array}\right)
$$

In the matrix $\bar{A}$ maximum is 4.26 . Consequently $B a=4.26$. The element $\bar{A}_{3}=4.21$ differs from $B a$ for less than $\Delta=0.5$.

According to formula (5) for the third strategy, the total probability is $P_{3}^{*}(>B a)=0.2+0.3=0.5$. There is only one element for the second strategy $a_{23}=7$ exceeds $B a=4.26$ with probability 0.3 which is less than $P_{3}^{*}(>B a)=0.5$. Therefore, a third strategy is preferred rather than a second one. 


\subsection{The Bayes criteria in terms of mining safety risks}

Consider the case when a decision maker needs to choose a strategy from several alternative strategies that ensures minimal risk.

The known risks $r_{i j}$ under the $i$ strategy $(i=\overline{1, m})$ and the $j$ state $(j=\overline{1, n})$ of geotechnical systems that form risk matrix $R$ the size of $m \times n$. The Bayes criterion determines the effectiveness of the strategy as the minimum average risk value.

$$
\begin{aligned}
& \bar{r}_{i}=\sum P_{j} r_{i j}, \\
& B a_{r}=\min _{i} \bar{r}_{i} .
\end{aligned}
$$

With the matrix notation, we have

$$
B a_{r}=\min \bar{R}=\min \left(R P^{T}\right)
$$

where $\bar{R}$ is the matrix column of the average mining risk values.

If we suppose that for the decision makers the acceptable increase in the Bayes criterion is by $\Delta_{r}$. For the strategies $S_{i}$ for which $\bar{R}_{i}$ is lying in $B a_{r} \leq \bar{R}_{i} \leq\left(B a_{r}+\Delta_{r}\right)$ the choice of a strategy is better than the existing $S_{B a_{r}}$.

For strategies $S_{i}^{*}$ in matrix $R$ we choose elements that are less than $B a_{r}$ and calculate the total probabilities:

$$
P_{i}^{*}\left(<B a_{r}\right)=\sum_{j=1}^{n} k_{j}
$$

where $k_{j}=\left\{\begin{array}{ll}P_{j}, & r_{i j} \leq B a_{r} \\ 0, & r_{i j}>B a_{r}\end{array}\right.$.

Let us also determine the total probabilities $P_{B a_{r}}^{*}\left(<B a_{r}\right)$ for strategy $S_{B a_{r}}$. If $P_{i}^{*}\left(<B a_{r}\right)<P_{B a_{r}}^{*}\left(<B a_{r}\right)$ then the reasonable decision would be to choose the strategy $S_{i}^{*}$. If there are several such strategies, a strategy with a higher probability of implementation would have an advantage.

Let us consider another example where there are still four states of complex geological conditions that describe rocks and soils with probabilities:

$$
P=\left(\begin{array}{llll}
0.1 & 0.2 & 0.25 & 0.45
\end{array}\right)
$$

Three strategies with a risk matrix (in arbitrary units) and deviation from $B a_{r}$ for less than $\Delta_{r}=0.1$.

$$
R=\left(\begin{array}{cccc}
1 & 4 & 5.6 & 4.5 \\
3 & 3.3 & 4 & 3.6 \\
5 & 6.8 & 3.3 & 2
\end{array}\right)
$$


Calculating from (8), taking into account the formulas (12) and (13), we obtain

$$
\bar{R}=R P^{\mathrm{T}}=\left(\begin{array}{cccc}
1 & 4 & 5.6 & 4.5 \\
3 & 3.3 & 4 & 3.6 \\
5 & 6.8 & 3.3 & 2
\end{array}\right)\left(\begin{array}{l}
0.1 \\
0.2 \\
0.25 \\
0.45
\end{array}\right)=\left(\begin{array}{l}
4.325 \\
3.58 \\
3.585
\end{array}\right) .
$$

In the column matrix $\bar{R}$ the minimum element is 3.58. Thus $B a_{r}=3.58$. For the third strategy, medium risk $\bar{R}=3.585$ differs from $B a_{r}$ for less than $\Delta_{r}=0.1$.

According to formula (11) for the third strategy, the total probability $P_{3}^{*}\left(<B a_{r}\right)=0.25+0.45=0.7$. For the second strategy, we have a lower probability $P_{2}^{*}\left(<B a_{r}\right)=0.1+0.2=0.3$, that is why the third strategy is more preferable than the second one.

\section{Conclusions}

The rational strategy choice for the mining development, taking into account the improved Bayes criterion, minimizes the risks of the complex mining and geological conditions impact on the mining efficiency. Taking into account the initial conditions of geotechnical systems with different probabilities of the geological conditions characteristics that describe rocks and soils, the rational development strategy choice for mining operations is considered and substantiated, in which the minimum risks are achieved for several alternative strategies with close values of performance indicators.

\section{References}

1. Y. Lapshyn, R. Molchanov. Improving the criteria for choosing the strategies in management by geotechnical systems. E3S Web of Conferences, International Conference Essays of Mining Science and Practice, 109 (2019). https://doi.org/10.1051/e3sconf/201910900048

2. A. Bulat, B. Blyuss. Modelling of deep wells thermal modes. Mining of Mineral Deposits, 13(1) (2019). https://doi.org/10.33271/mining13.01.058

3. B. Blyuss, L. Koriashkina. An optimal two-stage distribution of material flow at the fuel and energy complex enterprises. E3S Web of Conferences, International Conference Essays of Mining Science and Practice, 109 (2019). https://doi.org/10.1051/e3sconf/ 201910900008

4. Taha, Hemdi A. (2005). Vvedeniye v issledovaniye operatsiy. Moskva: Izdatelskiy dom Vilyams

5. Shiyan, A.A. (2009). Teoriia ihor: osnovy ta zastosuvannia v ekonomitsi ta menedzhmenti. Vinnytsia: VNTU

6. Petrushenko, M.M. (2012). The economic "games against nature": a model of decisionmaking in the field of environmental conflict. Biznes Inform, 4, 130-132

7. Shapkin, A. S., Shapknn, V. A. (2005). Teoriia riska $i$ modelirovaniye riskovykh situatsiy. Moskva: Izdatelsko-torgovaia korporatsiia Dashkov i $\mathrm{K}^{\mathrm{o}}$

8. Shubik, M. (2012). The present and future of game theory. Matematicheskaia teoriia igr i eye prilozheniia, 4, 1, 93-116

9. Labsker, L. G., Yaschenko, N.A. (2015). Ekonomicheskiye igry s prirodoy. Moskva: KNORUS 
10. Kaluski, Ya. (2011). Application of game theory in the planning and management of a mining enterprise's resources. Kompyuting, 10, 2, 172-178

11. Bulat, A.F., Bunko, T.V., Kokoulin, I.E., Yaschenko, I.A. (2017). The criteria for use of a risk matrix for the improvement of production management system and occupational safety and health in coal mines. Geotehnicheskaia mehanika [Geo-Technical Mechanics], 133, 228-238

12. Labsker, L.G., Yanovskaya, E.V. (2002). General methodology for constructing criteria for optimality of decisions in conditions of risk and uncertainty. Upravleniye riskom, 4, $13-24$

13. Mihaelis, V.V. (2016). Application of some criteria when choosing the optimal strategy in game theory. Informatsionnyie tekhnologii i problemy modelirovaniia slozhnykh sistem, 15, 89- 95

14. Vilchek, F. (2016). Krasota fiziki: postigaia ustroiystvo prirody. Moskva: Alpina nonfikshn

15. Utkin, L.V. (2007). Analiz riska i prinyatie resheniy pri nepolnoy informatsii. SPb.: Nauka 